\title{
Legal Framework and Implementation of Workforce Diversity Policies in Public Universities in Kenya
}

\author{
Catherine K. Kaimenyi ${ }^{1}$, Prof.Harriet J. Kidombo ${ }^{2}$, Dr.Thomas Senaji ${ }^{3}$ \\ ${ }^{I}$ Department of Business Administration, Chuka University \\ ${ }^{2}$ School of Continuing and Distance Education, University of Nairobi \\ ${ }^{3}$ School of Business and Economics, Kenya Methodist University
}

\begin{abstract}
This study sought to establish the influence of legal framework on the implementation of workforce diversity policies in public universities in Kenya.. A positivist paradigm using descriptive cross sectional survey research design is used. The population of the study comprised of employees of 22 Public Universities in Kenya that existed prior to December, 2014. Purposive sampling was used to select seven universities that participated in the study while Yamane's (1967) formula was used to calculate the sample size. A sample size of 393 was used from academic and non-academic staff from the participating universities. A structured questionnaire with Likert-type interval scale anchored on a five-point scale was used to collect primary data. Data analysis was done using linear regression model. The findings indicated that legal framework had a negative and statistically significant influence on implementation of workforce diversity policies. It is recommended that clarification of workforce diversity policies by policy makers and a change of mindset by implementers is necessary to enhance implementation.
\end{abstract}

Keywords: Workforce Diversity, Policy Implementation, Legal Framework, Gender, Ethnicity, Disability

\section{Introduction}

Societies around the world have become increasingly diverse, and the management of workforce diversity has become an issue driving public policies. Scientific management approaches based mainly on standardization have been replaced by new management theories that require organizations to foster a diverse workforce. Workforce diversity reflects the reality that people differ in many visible and invisible ways such as gender, ethnicity, culture, age, disability, religion, social status and personality traits (Schermerhorn, Hunt \& Richard, 2005, Reece \& Brandt, 1993).

Workforce diversity refers to the many differences among people which include primary dimensions like age, race, ethnicity, gender, mental/physical qualities and sexual orientation. It also extends to incorporate secondary characteristics like disparities in income, education religious beliefs and parental status (Schermerhorn, Hunt \& Richard, 2005; and Reece \& Brandt, 1993). Workforce diversity involves not only how people perceive themselves but also how they perceive others. Research has established that diversity enhances performance by broadening the group's perspectives and that successful diversity management and a resulting improvement in organizational performance are positively correlated (Ozblilgin and Tatli, 2008). The need to tap the creative, cultural, and communicative skills of a variety of employees and to use those skills to improve company policies, products, and customer experiences are more reasons why the benefits of workforce diversity cannot be underestimated (Rodriguez, 2006). To tap those benefits, nations around the world have advocated for inclusivity and developed policies to enhance diversity levels in their organizations. However, Although if adopted such policies have the potential to produce a more diverse and equitable society, there adoption has not been smooth, with some countries and organizations becoming insensitive in that matter (Wrench, 2005).

\subsection{Workforce Diversity Policies and Public Universities in Kenya}

In Kenya, workforce diversity is promoted largely through the Constitution, 2010. Article 81 (b) for example, outlines that not more than two-thirds of the members of elective public bodies shall be of the same gender. Article 55 further provides that the government shall take measures to ensure the youth have opportunities to participate in political, social and economic spheres of life and access to employment. Moreover, Article 56 provides for affirmative action for minorities and marginalized groups in employment. The public service of Kenya is required by the Constitution (Article 232, h) to have representation of Kenya's diverse communities and afford adequate and equal opportunities for appointment, training and advancement at all levels of men and women and members of all ethnic groups. Persons with Disabilities (PWD) should form at least 5\% of the workforce (Article, 54, 2). 
Public universities in Kenya fall under state corporations, which have undergone tremendous changes especially with the implementation of Public Sector Reforms of 2002 and after, transparency and accountability were given attention. As Kenya becomes more sophisticated and with mounting numbers from diverse communities, races, religious backgrounds and other workforce diversity dimensions assessing higher education, it is paramount that a diverse workforce is inevitable. Zusman (2005) recognized that universities of the 21 st century experience philosophical challenges to the nature, values, and control of universities. Strictly adhering to the set policies such as those stipulating workforce diversity composition will not only help reduce conflict but also give universities a competitive edge in the market.

In the recent past, universities in Kenya have attracted scrutiny on claims of ethnic imbalances in employment. According to a study by National Cohesion and Integration Commission (NCIC, 2012), massive gaps existed in ethnic composition of public universities workforce, with some communities not represented at all. One of the study findings was that the five largest communities who make up to about $66 \%$ of the Kenya population, constituted over $81 \%$ of the total public university workforce. Although a more recent draft report by the commission (NCIC, 2016) shows some improvement where the five communities now hold $70.8 \%$ from the previous $81 \%$, more needs to be done to enhance ethnic equity in employment. The Commission's 2012 report indicated that most of the staff in the universities came from the communities within which those institutions were located. Further revelations by the NCIC research indicated that majority of the employees in public universities and constituent colleges came from the same ethnic group as the Vice Chancellor and Principal. Representation of the majority of the senior staff at universities and constituent colleges was also consistent with the representation of the majority ethnic community at the institutions. Besides, a study by Onsongo (2011) in three public universities established an enormous gender gap in employment, where women occupied lower ranks as academic staff. The study reveals that women professors accounted to $3.6 \%$ while the Associate Professors accounted to $18.9 \%$. At the level of Senior Lecturers and Lecturer, women accounted for $22.4 \%$ and $26.1 \%$ respectively. At the Assistant Lecturer level $29 . \%$ were women while $36.8 \%$ of the tutorial fellows were women. This was consistent with the study by the Ministry of Gender, Children and Social Development (2011) on civil service employment where women in job Group P and above in the ministry of Higher Education were only $18 \%$ of the workforce.

\subsection{Statement of the Problem}

Workforce diversity is a human resource management concept that originally developed in the United States in the 1980s and becoming increasingly popular in other cultural contexts, including new immigrant nations such as Argentina, Australia, Brazil, Canada, New Zealand and South Africa (O'Leary, 2009). A diverse workforce has been commended for its potential to create organizational harmony, improve productivity and assist the understanding of greater customer needs. In its efforts to leverage these benefits, the government of Kenya has developed policies which should guide staffing procedures. Yet a gap exists between the diversity policies and implementation.

In the past universities have lost staff in what is commonly termed as 'brain drain' depriving the country of much needed talent. An example is Kenyatta University which lost 20 lecturers in a span of one year (Wasyonju , Kindiki, \& Kali, 2012). Staff in these institutions have joined workers unions like University Academic Staff Union (UASU) and Kenya Universities Staff Union (KUSU) to fight for an equal and inclusive workplace where employment, training, promotion and other opportunities are distributed in an equitable manner. Reports by NCIC indicate ethnic inequality in the workforce of public universities. Further, gender and disability research in the same sector show some disparities between WDPs and their implementation.

Several studies have been conducted in the area of workforce diversity in Kenya. For instant, there are those focusing on strategies for managing workforce diversity (Kinyanjui, 2013), workforce diversity management and employee performance, (Munjuri \& Maina, 2013), top management team workforce diversity (Zachary, 2013), challenges of managing diverse workforce (Heike, Edeltraud \& Gumato, 2011), importance of managing workforce diversity (Tabitha., et. al. 2013) and effects of workplace workforce diversity management on organizational effectiveness (Otike, Omboi \& Mwalekwa, 2011). Other studies have focused on only one variable of workforce diversity like gender (Osumba, 2011) and ethnicity (Yieke, 2010). There is little evidence of research specifically in the area of workforce diversity policy implementation. This study therefore seeks to bridge the gap by examining the influence of the legal framework on implementation of workforce diversity policies in public universities in Kenya. 


\section{Literature Review}

Among the early scholars in policy implementation were Pressman and Wildavsky (1973) who argue that proper implementation requires government officials to translate broad agreements into specific decisions and offer consistent support. Further, Bhola (2004) suggests that policy implementation is a process 'to actualize, apply and utilize the policy in the world of practice. For workforce diversity policies to get effect implementation, they should be clearly stipulated to enable clear actualization and application. Although literature suggests both the top-down and bottom-up approaches to policy implementation (Hill, 2005), this study utilizes a top-bottom approach because diversity policies are usually developed from the leadership and passed down for implementation.

Literature in the field of policy implementation has identified various reasons why good policies fail. For example Ali (2006) revealed that polices in Pakistan's education sector fail due to lack of clarity of policy goals, political commitment of leadership, governance structures, centralization, resource constraints, and influence of donors. Poor implemented beliefs and value system, compounded by power control which in turn leads to resistance to change has also been blamed for the gap between policy formulation and implementation. This is the result of high centralized system discussed by Ali (2006). According to Chaneta (2012), poorly developed policies that do not align to the broad organizational strategy are to blame for failure of implementation. From this view, it can be deduced that if diversity policies are viewed as complex and unimportant and so a cost to the organization, they are likely to face a challenge in implementation. It is on this basis that the study hypotheses were developed.

Drawing from the policy implementation models, and adopting the organizational perspective for the need for a diverse workforce, there is an implication that the degree of clarity of diversity policies as well as costs attributable to their implementation determines the degree to which such policies are implemented. According to Ali (2006), clarity of policy is crucial for organizations to understand the structure, provisions, rationale and even implication of policy implementation. The study therefore hypothesized that:

\section{H1: There exists no significant relationship between diversity policy clarity and the rate of their (policies) implementation in public universities in Kenya.}

Further, broad literature review by scholars like O'Leary (2009), Gray (2011) and Cedric (2009) reveal that organizations are keen to embrace workforce diversity when they attribute it with consequent benefits. The reverse is true where diversity is construed as having resultant costs and challenges to the organization (Kate, Mark, David \& Anthony,(2011) and Liswood (2010). This view leads to the development of the second hypothesis that:

\section{H2: There is no significant relationship between the cost associated with implementing workforce diversity policies in public universities in Kenya and the rate of their (policies) implementation}

\section{Research Methodology}

A descriptive cross-sectional survey was used to collect data as it afforded the opportunity to capture population's characteristics and test hypotheses from the seven of the twenty two public universities that existed by 2014. The seven included University of Nairobi (UoN), Kenyatta University (KU), Jomo Kenyatta University of Agriculture \& Technology (JKUAT, Maseno University, Moi University, Egerton University and Maside Muliro University of Science and Technology (MMUST).

Several factors were considered to arrive at the choice of the participating universities. First, the NCIC (2012) survey that reported massive discrimination in workforce diversity focused on these universities. These universities would therefore provide most appropriate answers to the study questions. Second, nearly all the other public universities were constituent colleges of the seven and so are well represented by their 'mother' universities. Third, the seven universities have been in existence longer than the others and likely to have a workforce that has a relatively longer service thereby being in a position to respond in a more informed manner to the research questions. Finally, the seven universities command more than $70 \%$ of the total workforce of the public universities in Kenya. A sample of 393 was selected which includes 125 and 268 individuals from teaching and non-teaching staff respectively.

\subsection{Research Instruments}

The researcher used questionnaires to gather primary data from the academic and non-academic staff from selected public universities. The questionnaire was divided into seven parts. Part one obtained data on 
respondents' profiles and other general information. Part two of the questionnaire was used to collected data on clarity of policy. Further, Part three was used for data on costs associated with policy implementation while Part four captured data on implementation of workforce diversity policies. Unlike Part one which had both openended and close-ended questions to enable respondents clearly specify their profiles, all other parts contained closed-ended questions only. Closed ended questions give precise information which minimizes information bias and facilitates data analysis (Cooper \& Schindler, 2007). The study determined the reliability of each study variable by computing Cronbach's Alpha Coefficient which stood at 0.876, indicating a high level of consistency. Validity was tested through carrying out a pilot study where the instrument was then modified and results incorporated in the final statements used for data collection.

\subsection{Data Collection Procedures}

Due to the large number of respondents involved in the study, two research assistants were engaged and briefed on how to approach the universities, introduce themselves and how to distribute the questionnaires to the respondents in the universities. They were trained and sensitized on the content of the questionnaire, data collection methods and procedures, time management, communication and issues of ethics. As a control measure to ensure that the research assistants actually visited the universities and engaged the respondents, they were required to follow a planned schedule where the researcher would make impromptu visits to ascertain that they were actually doing the job. This way monitoring of data collection progress was achieved.

The questionnaires were distributed using a drop and pick method. The respondents were given a maximum of one week after which the questionnaires were collected. A cover letter from the researcher was attached to the questionnaire detailing the purpose of the study, encouraging participation, assuring respondents of confidentiality and thanking them for their cooperation.

\subsection{Data Analysis}

Data was analyzed using both descriptive and inferential statistics. Descriptive statistics namely frequencies, percentages and measures of central tendency especially the mean, standard deviation and coefficient of variations were used to describe the characteristics of the collected data. To determine the relationship between clarity of diversity policies and cost of implementation of workforce diversity policies and also test the hypothesized relationships, fundamental statistical measures such as correlation analysis and regression analysis were used. According to Kothari (2009) analysis of variance is used because it makes use of the $\mathrm{F}$ - test in terms of sums of squares residual. Pearsons product moment correlation was derived to show the nature and strength of the relationship between variables. Coefficient of determination $\left(\mathrm{r}^{2}\right)$ was used to measure the amount of variation between the independent and dependent variables.

The following research model was adopted for this study;

IWDP $=\beta_{\mathrm{o}}+\beta_{1} \mathrm{X}_{1}+\beta_{2} \mathrm{X}_{2}+\mathrm{e}$

In function form this model can be expressed as follows:

IWDP $=f\left(X_{1}, X_{2}, e\right)$

Where

IWDP = Implementation of Workforce Diversity Policies

$\mathrm{X}_{1} \quad=$ Clarity of diversity policies

$\mathrm{X}_{2} \quad=$ Cost of diversity policy implementation

$\beta_{\mathrm{o}} \quad=$ Constant

$\beta_{\mathrm{i}} \quad=$ Regression coefficient at $i$ th variable $(\mathrm{i}=1,2)$

$\mathrm{e} \quad=$ Error term (the error is assumed to be normally distributed with a mean of zero and a constant variance of one)

\section{Results and Discussion}

The sample response rate was $94 \%$, a high rate in comparison with others in similar field. For example, Shah et al (2012) in a Pakistani University recorded a response rate of 56\% while Omari (2012) who carried a study in public state corporations in Kenya had a response rate of $48 \%$. Of these, $59.1 \%$ were male while $40.4 \%$ were female. This shows that data collection met the two-thirds gender policy advocated by the Constitution of Kenya (2010). The highest category of respondents fell under the age group between $31-40$ years comprising of $46.3 \%$ of the total respondents. Only $10.2 \%$ and $0.5 \%$ represented the categories aged over 50 and less than 20 years respectively. Education wise, the respondents had a relatively high level of education with $40.1 \%$ and $25.7 \%$ holding postgraduate and graduate qualifications respectively. 


\subsection{Descriptive Statistics}

The study explored the means and standard deviations (SD) of the legal framework (independent variables) and implementation of workforce diversity (dependent variable). The study set to establish the influence of the legal framework on the implementation of workforce diversity polices in public universities. Implementation of workforce diversity policies was indicated by the ratios of men to women and percentage of PWDs as well as ethnic composition in the institutions. Respondents were required to indicate the extent to which their universities paid attention to defined perspectives in statements focusing on the study variables. Statements were anchored on a five point Likert scale ranging from $1=$ Strongly Disagree to $5=$ Strongly Agree. Mean scores of sub-set statements as well as the aggregate averages were computed. A mean score of 2.5 indicated an average rating while means above or below represented a high or low measures in descending or ascending order respectively. Standard deviation was also computed as a measure of variations from the mean. A small SD indicates that most of the sample means lies near the middle while a large SD implies that the sample mean is spread out over a large rate of values (Harper, 2000). As opposed to large SD, small SD is a good estimator of the population mean.

\subsubsection{Clarity of Diversity Policies}

The study set to establish the extent to which regulatory requirement for workforce diversity is clearly understandable. A set of eight items was developed where respondents were required to state their level of agreement/disagreement using a 5-Point Likert scale ranging from strongly disagree (1) to strongly agree (5). The results are presented in Table 4.15

Table 1 Respondents Scores on Policy Clarity and Implementation

\begin{tabular}{|c|c|c|c|}
\hline Clarity of Diversity Policies & $\mathbf{N}$ & Mean & SD \\
\hline There is no clear framework for implementing the policies that require a diverse workforce & 352 & 4.38 & .068 \\
\hline The university has a moral obligation to give preference to the minorities in its recruitment process & 352 & 1.93 & .078 \\
\hline $\begin{array}{l}\text { Justice means that all should compete equitably for employment positions without reserving some } \\
\text { for minorities }\end{array}$ & 351 & 4.52 & .065 \\
\hline The requirement for ethnic balance in employment is not well understood by the organization & 351 & 4.47 & .067 \\
\hline The process of balancing the workforce in hiring consumes a lot of the university's resources & 347 & 4.39 & .069 \\
\hline $\begin{array}{l}\text { The university considers the minorities in employment not for compliance with legal requirements } \\
\text { but because it is the right thing to do. }\end{array}$ & 361 & 1.84 & .075 \\
\hline It is unethical to deny a person employment in favour of one considered a minority & 353 & 4.54 & .063 \\
\hline The university require guidance to assist in compliance with affirmative action policies & 364 & 4.42 & .068 \\
\hline Composite Mean Score & 354 & 3.81 & .069 \\
\hline
\end{tabular}

The results in Table 1 show that overall mean score for the eight statements used to measure the clarity of workforce diversity policies was $3.81, \mathrm{SD}=.069$. This is an indication that diversity policies are perceived to be complex. Universities are likely to comply more where the requirements and procedures are simple than when they are complex. Among the statements ranking high was on justice (mean=4.52, $\mathrm{SD}=0.065$ ). This means that respondents held a view that affirmative action was wrong since all should compete equally for positions. This opinion is consistent to Rawl's theory of justice (1971) that justice means giving each person what they deserve, in this case equal opportunity through equal treatment. Ethics (mean= 4.54, $\mathrm{SD}=0.063$ ) supported the statement that it is wrong to deny a person employment opportunity in favour of one considered a minority. This makes the policies complex because different cultures have different ethical systems which may make it difficult to have standard parameters on which to measure the level of ethical behaviour. It could also indicates that workforce diversity regulatory requirements have ethical imperatives that need to be addressed to improve compliance.

The statement that the university considers the minorities in employment not for compliance with legal requirements but because it is the right thing to do attracted the lowest mean (mean=1.84, $\mathrm{SD}=0.075$ ) indicating a perceived no good will from the institutions to implement diversity workforce policies. This may be a reason why diversity policies are not getting the attention they deserve. Similarly, results demonstrated a low opinion (mean $=1.93, \mathrm{SD}=0.078$ ) that universities have moral obligation to give preference to minorities. This could be an indication that people are more concerned with ventures that would yield tangible benefits as opposed to those that appear to have social responsibility dimensions.

\subsubsection{The Cost of Compliance with Workforce Diversity Policies}

The current study sought to determine the extent to which organizations regard compliance with the workforce diversity polices as either a cost to be minimized or benefit to be enhanced. To measure the cost/benefit of compliance with workforce diversity, a set of eight items was used. The relevant results are summarized in Table 2. 
Table 2 Respondents Scores on Compliance Cost/Benefit

\begin{tabular}{|c|c|c|c|}
\hline Compliance Cost/Benefit & $\mathbf{N}$ & Mean & SD \\
\hline The cost of complying with affirmative action policies in the university supersedes its benefits & 358 & 4.32 & .072 \\
\hline Affirmative Action kills the spirit of competition for job positions & 357 & 4.23 & .071 \\
\hline Affirmative Action brings in unqualified people in the workplace & 351 & 4.23 & .070 \\
\hline Trying to recruit a diverse workforce in terms of tribes may compromise the recruitment process & 352 & 4.18 & .071 \\
\hline Implementing workforce diversity policies is beneficial to the university & 349 & 1.94 & .077 \\
\hline $\begin{array}{l}\text { Unqualified persons with disabilities are employed in place of others who may be more qualified to } \\
\text { meet policy threshold }\end{array}$ & 356 & 4.33 & .070 \\
\hline Having a diverse workforce improves the public image of our organization & 351 & 3.42 & .068 \\
\hline $\begin{array}{l}\text { Giving special consideration to persons with disability is tantamount to discrimination against } \\
\text { others. }\end{array}$ & 357 & 4.24 & .075 \\
\hline Composite Mean Score & 354 & 3.86 & .072 \\
\hline
\end{tabular}

Results in Table 2 indicate that legal framework is perceived to be characterized by a relatively high cost implications to implement workforce diversity policies with a mean score $=3.86$, SD 0.072. In particular, respondents indicated that in comparison to its benefits, the cost of complying with affirmative action policies was higher (mean=4.32, $\mathrm{SD}=0.072$ ). This was in spite of majority of respondents indicating a lowly ranking implementation of workforce diversity policies as beneficial to the university with a mean score of 1.94 , $\mathrm{SD}=077$. This mean score (1.94) indicates that respondents do not see value in implementing diversity policies since it is costly, and perhaps because of their personal interests or selfishness thereby preferring those with backgrounds similar to theirs. Public image as a benefit of compliance attained highest ranking at mean $=4.42$, $\mathrm{SD}=.075$. These results may imply that organizations may be influenced to comply with workforce diversity policies depending on their perceived cumulative costs/benefits. Since organizations would generally work to minimize costs, implementation of workforce diversity policies would not be favored due to the perceived associated cost.

\subsubsection{Implementation of Workforce Diversity Policies}

Policy implementation is a process to actualize, apply and utilize it [policy] in the world of practice (Bhola, 2004). Goals in terms of laws, guidelines and regulatory requirements have been put in place in Kenya stipulating that the organizations should ensure diversity of opportunity in terms of gender, ethnicity and persons with disability. Following those stipulations would result to workplace representation/balance. This study identifies ethnic composition, gender and physical ability/disability dimensions as indicators for the degree to which workforce diversity policies have been implemented. Information of ethnic compositions was derived from respondents using primary data while those of gender and disability used secondary data from universities' websites and records.

\section{(a) Ethnic Composition}

Ethnicity is used interchangeably with tribalism to mean a group of people who share the same culture and identity including language, geographical location and behaviour norms and attitude (Cybulski, 2005). When people share a tribe, they are likely to give favors to other members even when it is not due to them. To measure the ethnic composition in public universities, five items were developed where respondents were asked to state how strongly they agreed with related statements. Results are presented in Table 3

Table 3 Respondents mean Scores on Ethnic Composition of the Workforce

\begin{tabular}{|l|l|l|l|}
\hline Ethnic Composition & $\mathbf{N}$ & $\mathbf{M e a n}$ & SD \\
\hline No single community has more than 30\% representation in the University's workforce & 372 & 2.13 & .079 \\
\hline The university has maintained the regional balance in its employment over the last five years & 368 & 2.05 & .075 \\
\hline $\begin{array}{l}\text { Unrepresented communities have been given priority for employment positions over the last } \\
\text { five years }\end{array}$ & 365 & 1.97 & .074 \\
\hline Regional representation in the workforce is satisfactory & 364 & 1.89 & .074 \\
\hline The university workforce reflects the face of Kenya & 372 & 1.91 & .072 \\
\hline Composite Mean Score & $\mathbf{3 6 8}$ & $\mathbf{1 . 9 9}$ & $\mathbf{. 0 7 4}$ \\
\hline
\end{tabular}

Results in Table 3 show that the average mean score for ethnic composition of the workforce is 1.99 , $\mathrm{SD}=.074$. Generally the mean scores of all items are below average ranging from the highest mean score of $2.13, \mathrm{SD}=.079$ to the lowest mean score of $1.89, \mathrm{SD}=-074$. This means that public universities are perceived to have a workforce that does not reflect the face of Kenya as far as ethnicity is concerned. The results are consistent with the NCIC (2012) study which revealed a huge tribal imbalance in public universities in Kenya. This suggests that diversity policies on ethnic dimensions are poorly implemented. Results of ethnic composition indicates that the public universities are perceived to have a workforce that does not reflect the face 
of Kenya (mean=1.99, SD=0.074). This supports the study by NCIC (2016) that the five biggest communities in Kenya occupy $70.8 \%$ of jobs in public universities.

\section{(b) Gender Representation and Proportion of Persons with Disability}

Gender representation was indicated by the ratio of men to women. Regulatory requirements stipulate that no more than two-thirds (33\%) of the workforce should be of the same gender in any public organization. Absolute data on the ratio of women to men was collected from the respective universities as percentages. The scale used denoted that an institution where either gender accounted to $0-10 \%$ was ranked as very poor, (11$20) \%=$ poor, $(21-30) \%$ as fair, $(31-40) \%=$ good while those with $(41-50)$ were ranked as very good. This scale was then converted to a five point likert scale from 1-5 in ascending order. It was then aggregated and average mean scores calculated.

Regarding persons with disability, the Constitution of Kenya states that category should be given opportunities in public sector to reflect at least $5 \%$ of the workforce. To establish the composition of the public universities workforce in terms of disability, data was gathered from the universities records as well as contacts with the relevant officers in those institutions. It was converted to a scale to ease calculation of average mean scored. Where persons with disabilities accounted for less than $2 \%$, this was rated as very poor, $3 \%=$ poor, $4 \%=$ fair, $5 \%=$ good and greater than $5 \%=$ very good. A 5-point likert scale was then used in ascending order of the percentages. Results are presented in Table 4

Table 4 Mean Scores of Gender and Disability Representation

\begin{tabular}{|l|l|l|l|}
\hline Gender and Disability & N & Mean & SE \\
\hline Gender Representation & 374 & 2.98 & 0.066 \\
\hline Disability proportion & 373 & 1.99 & 0.028 \\
\hline
\end{tabular}

Results in Table 4 indicate a fair gender representation in public universities (mean=2.98, SD $=0.066$ ). This implies that the workforce fall within the regulatory requirement of the two-thirds gender policy (between $31-40 \%)$. These results may imply that public universities are striving to comply with the two thirds gender policy because this is an improvement from Onsongo (2009) where female academic staff accounted for only about $26 \%$. The mean score for persons with disability was poor (mean=1.99, $\mathrm{SD}=0.028$ ) indicating that the institutions fall far below the minimum requirement of 5\% stipulated by the Constitution. This could be attributed to the complexity and cost involved in implementing such policies. For example, diversity policies do not spell out the process that should be followed in recruitment of PWD or the explanation of who qualifies to be included in this category.

\subsection{Correlation Analysis Results}

The Study employed Correlation analysis using Pearson Product moment correlation coefficient technique to establish the relationship between policy the policy clarity, cost of implementation and implementation of WDP and the results are indicated in Table 5.

Table 5: Correlation Analysis Matrix

\begin{tabular}{|c|c|c|c|c|}
\hline & & 1 & 2 & 3 \\
\hline \multirow{3}{*}{$\begin{array}{l}\text { 1.Implementation of workforce } \\
\text { diversity policies }\end{array}$} & Pearson Correlation & 1 & & \\
\hline & Sig. (2-tailed) & & & \\
\hline & $\mathrm{N}$ & 373 & & \\
\hline \multirow{3}{*}{$\begin{array}{l}2 . \\
\text { Clarity }\end{array}$} & Pearson Correlation & $-.773^{* *}$ & 1 & \\
\hline & Sig. (2-tailed) & .000 & & \\
\hline & $\mathrm{N}$ & 360 & 371 & \\
\hline \multirow[t]{3}{*}{ 3. Cost of Implementation } & Pearson Correlation & $-.640^{* *}$ & $.671^{* *}$ & 1 \\
\hline & Sig. (2-tailed) & .000 & .000 & \\
\hline & $\mathrm{N}$ & 371 & 373 & 372 \\
\hline
\end{tabular}

**.Correlation is significant at the 0.01 level (2-tailed).

The results in Table 5 indicate that the relationship between policy clarity and implementation of WDP is strong, negative and statistically significant $(r=-.773$, $\mathrm{p}$-value $=0.000<0.05)$. This implies that an increase in policy complexity decreases implementation of workforce diversity policies and vice versa in public universities. Similarly the relationship between cost of implementing diversity policy and the level of implementation is moderately negative and statistically significant $(\mathrm{r}=-.640$, $\mathrm{p}$-value $=0.000<0.05)$. This implies that the more implementation of the policies is perceived the less the level of it implementation and vice versa.

\subsection{Hypothesis Testing}

This study was based on the premise that there is a relationship between the legal framework and 
implementation of workforce diversity policies in public universities. Two hypotheses were developed in line with these relationships. To establish the statistical significance of the respective hypothesis, regression analysis was conducted at $95 \%$ confidence level.

\subsubsection{Policy Clarity and Workforce Diversity Policies}

The study sought to establish the relationship between the diversity policy clarity and the level of their implementation in public universities in Kenya and sought to test the hypothesis that:

\section{H1: There exists no significant relationship between diversity policy clarity and the rate of their (policies) implementation in public universities in Kenya.}

Pertinent results are indicated in table 6

Table 6 Policy Clarity and Workforce Diversity Policies

\begin{tabular}{|c|c|c|c|c|c|c|c|}
\hline \multicolumn{8}{|c|}{ (a) Goodness of Fit } \\
\hline $\mathrm{R}$ & \multicolumn{3}{|c|}{ R. Square } & \multicolumn{3}{|c|}{ Adjusted R.Square } & Std.Error of Estimate \\
\hline $856^{\mathrm{a}}$ & \multicolumn{3}{|c|}{746} & \multicolumn{3}{|c|}{.746} & .67638 \\
\hline \multicolumn{8}{|c|}{ (b) Overall Significance } \\
\hline & $\begin{array}{l}\text { Sum } \\
\text { Squares }\end{array}$ & & $\mathrm{df}$ & $\begin{array}{l}\text { Mean } \\
\text { Square }\end{array}$ & $\mathrm{F}$ & & Mean Square \\
\hline Regression & 451.734 & & 1 & 441.733 & 1007.15 & & Sig. \\
\hline Residual & 161.644 & & 362 & 440 & & & $.000^{\mathrm{a}}$ \\
\hline Total & 613378 & & 363 & & & & \\
\hline \multicolumn{8}{|c|}{ (c)Individual Significance } \\
\hline & \multicolumn{3}{|c|}{$\begin{array}{l}\text { Unstandardized } \\
\text { Coefficients }\end{array}$} & \multicolumn{2}{|c|}{ Standardized Coefficients } & & \\
\hline Model 1 & $\mathrm{~B}$ & & Error & Beta & & T-Value & Sig. \\
\hline (constant) & 7.678 & & & & & 41.205 & .000 \\
\hline Clarity of WDP &.-1.502 & .0 & & -.855 & & -31.884 & .000 \\
\hline
\end{tabular}

The results in Table 6 show that diversity policy clarity had a statistically significant influence on implementation of WDP. The hypothesis is thus rejected. These results explained a variation of $74.6 \%$ $\left(\mathrm{R}^{2}=0.746\right)$. The Regression coefficient value of the computed scores of policy clarity -1.502 with a t-test of 31.884 and a significant level of $\mathrm{p}<0.001$. This implies that complexity faced in implementation of WDP decreases the level of its implementation. It was found that the overall significance in the model suggest the regression was statistically significant at $5 \%(\mathrm{~F}=1007.15$; $\mathrm{P}$-value $=0.000)$. Previous studies by Bass and Paikei (1999) on strategies for managing human resource diversity revealed that to succeed in diversity initiatives, management must effectively manage resistance to change. This, according to that study would change the perceptions held such as those portraying other demands like global competition to be more immediate.

\subsubsection{Cost /Benefit analysis and Workforce Diversity Policies}

The study sought to establish the relationship between the cost of implementing workforce diversity policies and the rate of policy implementation by testing the hypothesis that:

H2: There is no significant relationship between the cost associated with implementing workforce diversity policies in public universities in Kenya and the rate of policy implementation

Results are summarized in Table 7

Table 7 Cost of implementation and Workforce Diversity Policies

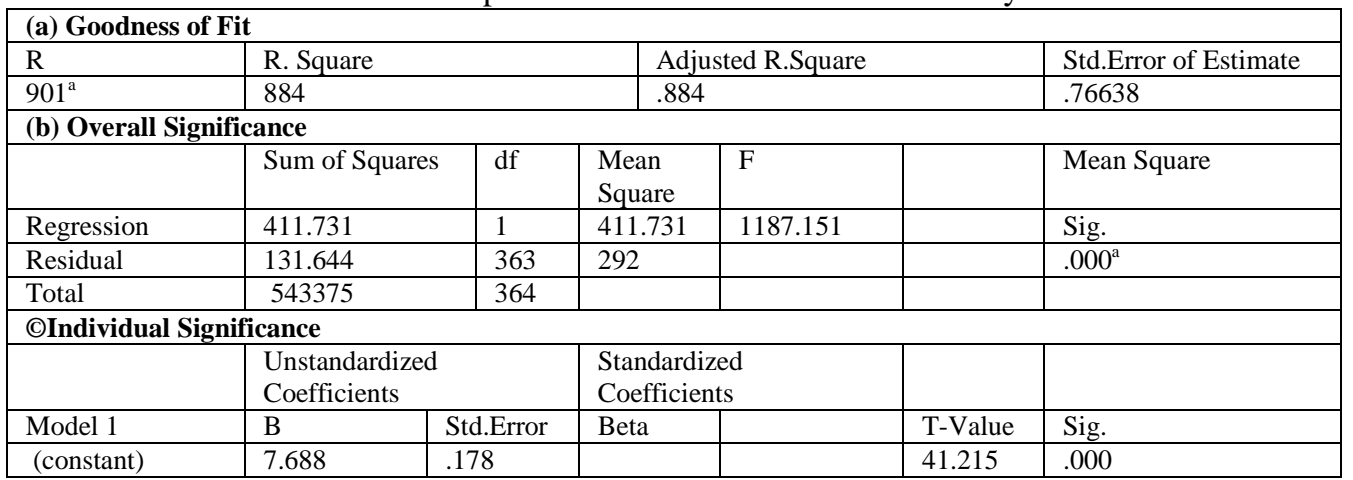




\begin{tabular}{|l|l|l|l|l|l|l}
\hline Compliance cost &.-999 & .044 & -.855 & & -41.874 & .000
\end{tabular}

The results in Table 7 indicates that the compliance cost of implementing WDP had a statistically significant influence on implementation of workforce diversity policies explaining a $88.4 \%$ of its variation $\left(\mathrm{R}^{2}=0.884\right)$. The hypothesis is therefore rejected. The Regression coefficient value of the computed scores of compliance cost was -.999 with a t-test of -41.874 and a significant level of 0.000 . This implies that an increase in compliance cost decreases the overall implementation of workforce diversity policies. The study findings are consistent with Richard (2000) that most firms interpreted workforce diversity as a human resource cost to be minimized and would employ all kind of strategies to avoid such costs.

\section{Conclusions and Recommendations}

From the study findings several conclusions and recommendations are drawn.

\subsection{Conclusion}

The study established that the legal framework was strongly negatively correlated with implementation of workforce diversity. This means that the perceived complexity and cost related to compliance with the legal requirement for workforce diversity reduces the degree to which public universities implement workforce diversity policies. The study findings revealed that policies on PWDs were not clear to employers, thus hindering effective implementation. It pointed out that employers may not have been exposed to successfully accommodate workers with disabilities.

Despite being entrenched in the Constitution it is clear from the study findings that there is a great deal more work to be done to enhance understanding of the intended purpose of the policies, the implementation processes, underlying challenges and potential benefits. The study established concerns that the potential expense of accommodating a worker with a disability are a major barrier as it contributes to a substantial financial burden to an organization. Such perceived financial implications may extend to infrastructure related costs of making workplace accessible, increased premiums for health insurance or workers compensation, legal and financial risk should a workplace injury or accident occur, as well as indirect costs like as extra supervision or time needed to complete tasks.

The findings further revealed that a gender gap exists in public universities where female employees are the minority. This means that although gender diversity policies broadly aim at bringing affirmative action for either gender, it is obvious that at the time of this study, women were the focus of diversity policies. Focusing more on women as workers in the public service through affirmative action would expose more women to leadership roles and thus provide models and mentors for the young career women. This eventually will lead to the long sought for gender equity at the workplace.

Although the legal framework as evidenced in the Constitution of Kenya provides that there should be representation of Kenya's diverse communities it does not spell out how this can be achieved. Similarly, no clear direction exists as to how equity in dimensions like promotion, training, and appointment opportunities for gender, disability and members of all ethnic groups is explained. For example a direction on what should happen in the event that the selection process does not get qualified candidates in line with the advocated balance and representation is missing.

\subsection{Recommendations}

The study established that the legal framework influences implementation of policies stipulating minimum requirements for gender composition, ethnic balance and PWDs ratios. Specifically, the complexity of implementing the 5\% policy on PWDs required by the Constitution was cited as one of the barriers. The study findings indicated that employers often lack an awareness of how to deal with and accommodate workers with disabilities. Based on this finding, the study recommends that the policy should be clarified to specify what disability means and how it can the policy can effectively be implemented. Modalities to implement the twothirds gender policy as well as the requirement that public organizations' workforce should reflect the face of the country need to be clarified for easier implementation. Further the study proposes a change of mindset by employers from the traditional stigmatization approach where PWDs were viewed as added burden to managers, supervisors, and human resource staff, to one where such diversities are valued and encouraged in organizations. This entails developing a new spirit of interpreting diversity policies based on goodwill and ownership of the policies.

\section{References}


[1]. Ali, S. (2006). Why Does Policy Fail? Understanding the Problems of Policy Implementation in Pakistan - A Neuro-Cognitive Perspective. International Studies In Educational Administration, 34(1), 1-20

[2]. Bhola, H. S. (2004) Policy Implementation: Planning And Actualization. Journal of Educational Planningand Administration, $18(3), 295-312$

[3]. Cedric, H. (2009). Does Workforce Diversity Pay: Race, Gender and the Business Case for Workforce Diversity. American Sociological Review, 74(2), $208-224$.

[4]. Chaneta, L. (2012). Strategic Management Process. Journal of Comprehensive Research, 5,12-19.http://jupapadoc. startlogic. com/compresearch/papers/JCR11-4.

[5]. Cooper, R. D. \& Schindler, S. P. (2006). Business Research Methods ( $9^{\text {th }}$ ed.). New Delhi-India. McGraw-HillPublishing Company.

[6]. Heike, M. K., Edeltraud, H. E. \& Gumato, U. (2011). Institutional Change: The impact of Kenya's new constitution on the workforce diversity of the public service sector. Retrieved from http://www.hbs.edu/faculty/conferences/

[7]. Kate, B., Mark, J.D., Davd, H., \& Anthony, W. (2011). Factors affecting the implementation of complex and evolving technologies Canada. BMC Health Services Research 11(1):11-78. DOI:10.1186/1472-6963-11-178

[8]. Liswood, L. (2010). Moving Beyond Workforce Diversity While Embracing Differences to achieve Success At Work. Hoboken, New Jersey: John Wiley \& Sons, Inc.

[9]. Kinyanjui, S. (2013). Innovative Strategies for Managing Workforce diversity in Kenyan Leading Corporations in Present Global Scenario. International Journal of Business and Management,8(15),2-32.Retrievedfrom http://dx.doi. org/10.5539/ijbm. v8n 15 p20

[10]. Kothari, C.R. (2009). Research Methodology: Methods and Techniques. New Delhi: New Age International Publishers

[11]. Munjuri, M.G., \& Maina, R.M. (2013). Workforce Diversity and Employee Performance in the Banking Sector in Kenya. DBA Africa Management Review, 3(1), 1 - 21 .

[12]. Ministry of Gender, Children and Social Development. (2011). Gender Policy.

[13]. NCIC. (2012). Briefs on Ethnic Workforce diversity of Public Universities in Kenya. Retrieved fromhttp:/ /www.cohesion. or.ke/

[14]. Omari S. (2012). The Influence of Contextual and Cognitive Factors on the Relationship between Employee characteristics and Employee Outcomes in Public Corporations in Kenya. (Unpublished. PhD Thesis. University of Nairobi)

[15]. Onsongo, J.K. (2011). Promoting Gender Equity in Selected Public Universities in Kenya, OSSREA.Retrievedfrom https://books. google.co. ke/books

[16]. Onsongo, J. K. (2012). Promoting Gender Equity In Higher Education: An Examination of Sustainable Interventions in Selected Public Universities in Kenya. Retrieved from http://www.kln.ac.lk/units/cgs/resources/OnsongoJanePromoting.pdf

[17]. Osumbah, B.A. (2011). Representation of Women in Top Educational Management and LeadershipPositionsinKenya. Advancing Women in Leadership. 31, -57-68. Retrieved from http://advancingwomen.com/awl/awl_wordpress

[18]. Otike, F. W., Omboi, B. M.\& Mwalekwa, F. K. (2011).Effects of Workplace Workforce DiversityManagementon Organizational Effectiveness: a case study. European Journal of Business and Management, 3(2), 50 - 64.

[19]. Ozbilgin M., Tatli A. (2008). Global diversity management: An evidence-based approach. London, England: Palgrave

[20]. Pressman, J.L. and Wildavsky, A.B. (1973). Implementation: How Great Expectation in Washington are Dashed in Oakland; or Why it's Amazing that Federal Program Works at all. Berkeley: University of California Press.

[21]. Republic of Kenya. (2010). The Constitution of Kenya.

[22]. Reece, B.L., \& Brandt, R. (1993). Effective Human Relations in Organizations (5 ${ }^{\text {th }}$ ed.) Boston: Houghton Mifflin Co.

[23]. Rodriguez R.(2006). Diversity finds its place. HR Magazine, 51, 56-61.

[24]. Schermerhorn, J. R., Hunt, J. G., \& Osborn, R. N. (2005). Organizational Behaviour (9th ed.). John Wiley \& Sons, Inc.

[25]. Wrench, J. 2005, 'Diversity management can be bad for you', Race and Class, 46, pp. 73-84.

[26]. Yamane, T. (1967). Statistics: An Introductory Analysis, $\left(2^{\text {nd }}\right.$ ed). New York: Harper and Row.

[27]. Yieke, F., (2010). Ethnicity and Development in Kenya: Lessons from the 2007 General Election. Kenya Studies Review, 3(3), $5-16$.

[28]. Zusman, A. (2005). Challenges Facing Higher Education in the Twenty-first Century. In Altbach, P G. \& Berdah R. O., American Education in the Twenty-first Century. Baltimore, MD: John Hopkins University. 